\title{
OLIGOPOLISTIC PRICE COMPETITION WITH INFORMED AND UNINFORMED \\ BUYERS
}

\section{Michal Ostatnický}
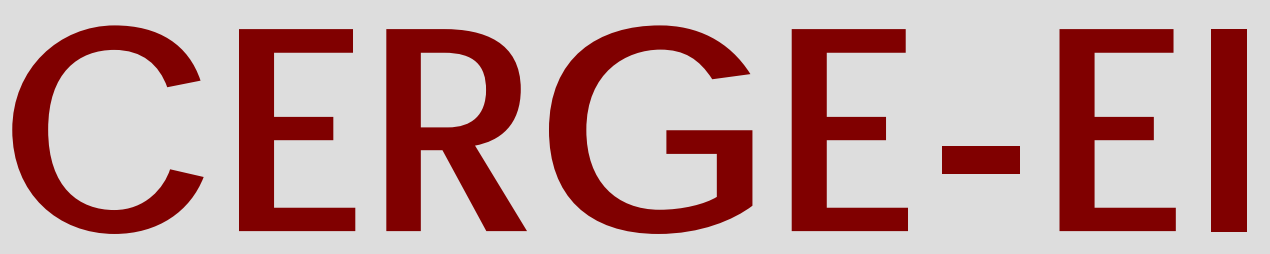

Charles University Centerfor Economic Research and Graduate Education Academy of Sciences of the Czech Republic Ec onomic Institute 


\section{Working Paper Series $\quad 413$ (ISSN 1211-3298)}

\section{Oligopolistic Price Competition with Informed and Uninformed Buyers}

Michal Ostatnický

CERGE-EI

Prague, August 2010 
ISBN 978-80-7343-211-9 (Univerzita Karlova. Centrum pro ekonomický výzkum a doktorské studium)

ISBN 978-80-7344-201-9 (Národohospodářský ústav AV ČR, v.v.i.) 


\title{
Oligopolistic Price Competition with Informed and Uninformed Buyers*
}

\author{
Michal Ostatnický ${ }^{\dagger}$
}

\author{
WP 413
}

\begin{abstract}
The standard price competition of two or more players leads to Bertrand equilibrium in basic economic theory (if complete information is assumed, there are no capacity constraints, etc.). In reality, even on highly competitive Internet-based markets, the prices of seemingly undifferentiated goods (e.g. books and CDs on Amazon and similar e-shops) vary, although competition seems prima facie based on prices. I follow the literature that originated with Varian's (1980) model, especially Kocas and Kiyak (2006), and analyze oligopolistic markets where buyers have reservation values drawn from a common distribution function rather than a single value (inelastic demand), as typically assumed in the models of Varian's or Kocas and Kiyak's type. The model presented in this paper is developed from the simplest symmetric set-up (uninformed buyers are assigned to sellers evenly) to the most complex asymmetric set-up with many competing sellers (uninformed buyers are distributed over sellers unevenly). The most complex set-up theoretically rationalizes the empirical findings of Kocas and Kiyak. In the equilibrium of my model, all sellers randomly choose prices from a non-trivial interval for (almost) every seller, while in Kocas and Kiyak's theoretical model only two sellers randomize while others always offer the same price.
\end{abstract}

\begin{abstract}
Abstrakt
Standardní soutěž v cenách dvou nebo více hráčů vede ve standardní ekonomické teorii $\mathrm{k}$ Bertrandově rovnováze (předpokládáme-li úplnou informaci, není omezována kapacita, atd.). $\mathrm{V}$ reálném prostředí, a to i v prostředí velmi fragmentovaného trhu na internetu, jsou ceny nerozlišitelného zboží (např́íklad knih a CD) různé, ačkoli se trh zřejmě řídí pravidly cenové soutěže. Vycházím z literatury, která se odvíjí od Varianova (1980) modelu, zejména ze studie Kocase a Kiyaka (2006) a studuji oligopolistické trhy, kde mají kupující cenové limity náhodně rozděleny, tj. není to jedna fixní hodnota jako $\mathrm{v}$ dosud publikované literatuře typu Varianovy studie nebo modelu Kocase a Kiyaka. Zde analyzovaný model je vyvíjen od nejjednodušší struktury (neinformovaní kupující jsou rovnoměrně rozděleni k prodávajícím), až po nejsložitější (nerovnoměrné rozdělení kupujících). Nejsložitější struktura dává racionální podklad empirickým zjištěním Kocase a Kiyaka. V rovnovážném bodě modelu (téměř) každý prodávající volí ceny náhodně $\mathrm{z}$ netriviálního intervalu, oproti tomu $\mathrm{v}$ teoretickém modelu Kocase a Kiyaka pouze dva prodávající volí ceny náhodně a ostatní volí vždy fixní cenu.
\end{abstract}

Keywords: oligopoly, price competition, price dispersion.

JEL classification: L11, D43.

\footnotetext{
*I would like to thank Andreas Ortmann who gave me valuable comments while writing this paper, Levent Celik for helpful comments in the last stage, and Avner Shaked for hints given during the early stages of writing this paper.

${ }^{\dagger}$ CERGE-EI is a joint workplace of the Center for Economic Research and Graduate Education, Charles University, and the Economics Institute of Academy of Sciences of the Czech Republic.

Address: CERGE-EI, P.O. Box 882, Politických vězňů 7, Prague 1, 111 21, Czech Republic
} 


\section{Introduction}

In this paper, I follow the literature on price dispersion. Using the concept of informed and uninformed buyers, I show that price competition with no capacity constraint can result in pricing that differs from the Bertrand equilibrium pricing and fits empirically observed behavior. Specifically, I derive a model that fits Kocas and Kiyak's (2006) empirical findings better than their own model.

The basic features of the model I develop in this paper have been applied before in a simpler, slightly different set-up. The informed buyers ${ }^{1}$ know the prices posted by all sellers and choose the seller with the lowest price, and the uninformed buyers ${ }^{2}$ choose sellers randomly. Sellers choose prices so that they benefit maximally from uninformed buyers (which entices sellers to choose high prices) and informed buyers (which entices sellers to choose low prices).

The literature on this topic was initiated by Salop and Stiglitz (1977), and followed by Varian (1980). ${ }^{3}$ These articles present models without sequential search in their articles. Consumers are either fully informed or never search and stay uninformed. Other examples of such models can be found in Braverman (1980), Stiglitz (1979), and Narasimhan (1988). In the present paper, I follow this precedent. ${ }^{4}$

Non-sequential, Varian-type search models have been applied to explain promotional strategies (Raju, Srinivasan, and Lal, 1990), international trade (Neven, Norman, and Thisse, 1991 or Baye and De Vries, 1992) and other applications where buyers may have an exogenously given tendency to prefer one product (seller) over another. All these models (with one laudable exception to be discussed presently) assume either a symmetry of sellers, meaning uninformed consumers are distributed paper, Levent Celik for helpful comments in the last stage, and Avner Shaked for hints given during the early stages of writing this paper.

${ }^{1}$ In the literature they are also called switchers, or searchers, even though search may not be modelled in the paper. I stick to the term "informed buyers" in this paper.

${ }^{2}$ In the literature they are also called non-searchers or loyal buyers.

${ }^{3}$ The model I derive in this paper is mainly based on Varian (1980) and Kocas and Kiyak (2006), so I refer to these models as Varian-type models.

${ }^{4} \mathrm{~A}$ related stream of literature does feature sequential search. Burdett and Judd (1983), Reinganum (1979), Stahl (1989), Stiglitz (1987), and Wilde and Schwartz (1979) are prominent examples. 
evenly over sellers, or a duopoly configuration. ${ }^{5}$

Recently, informed by Varian-type models, empirical researchers have used data collected from Internet e-shops (e.g. Clay, Ramayya, Wolff, and Fernandes, 2002; Clemons, Hann, and Hitt, 2002; or Iyer and Pazgal, 2003).

The most recent and most relevant research in the present context is Kocas and Kiyak (2006). These authors take the Varian (1980) model, where uninformed buyers choose a seller randomly (i.e. the probability an uniformed buyer chooses a specific seller is equal for all sellers) and add an asymmetry introduced by Narasimhan (1988): Uninformed buyers always go to "their" seller. The amount of uninformed buyers (which can be thought of as loyal) can be different for every seller. Kocas and Kiyak show that at most two sellers offer discounts, ${ }^{6}$ while others choose the monopoly price. This theoretical result does not correspond well to the reality of the online-book retailer market in which all sellers offer discounts. ${ }^{7}$ The authors enrich the model by seller-specific reservation prices to increase price dispersion. They fail, however, to get mixed strategies for all sellers as observed in reality. The result seems to be caused by the assumption of fixed reservation values. In this paper, I show that by relaxing this assumption and, instead, assuming that the reservation prices of all buyers are drawn from a commonly known distribution function, all sellers apply indeed mixed strategies. I also show that the lower bound of the support of the mixed-strategy distribution function is increasing with the increasing share of uninformed buyers. This result is in line with the empirical findings that Kocas and Kiyak provide.

I develop my model from the simplest set-up to the most complex, analyz-

\footnotetext{
${ }^{5}$ Additionally, Sinitsyn (2008) theoretically characterizes the basic features of the Varian-type model class. He shows that for a Varian-type model with heterogeneous tastes, a mixed-strategy equilibrium exists and identifies the basic features of the support of the equilibrium strategies.

${ }^{6}$ Offering a discount implies that they follow a mixed strategy in equilibrium. The mixed strategy nature of the equilibrium is standard in non-sequential, Varian-type models. The mixed strategy equilibrium results from optimal price-setting to capture the informed buyers (setting a low enough price to beat competitors) and to gain from the uniformed ones (setting a high enough price). Kocas and Kiyak show that in their set-up "only those with the least to lose from deep price cuts will offer discounts" (Kocas and Kiyak, 2006, page 90), and others do not want to compete and sell only to the uninformed buyers.

${ }^{7}$ The fact that all sellers offer discounts is empirically documented in their article; see Figure 3 of Kocas and Kiyak (2006).
} 
ing gradually symmetric duopoly and oligopoly (section II) and then asymmetric duopoly and oligopoly (section III). ${ }^{8}$ Section IV concludes.

\section{Symmetric model}

I start the analysis with the simplest possible model: symmetric duopoly. Two sellers offer undifferentiated products. Both sellers have to post a price so that everyone can buy the product at the given price, and they cannot discriminate between individual buyers. There is a mass of potential buyers willing to buy one unit of the product. Each buyer has a reservation value drawn from a commonly known distribution function; the reservation value itself is the private information of each buyer.

A buyer can either be informed about prices posted by the sellers or be uninformed. An informed buyer either buys one unit of the product from the seller with the lower posted price (if it is lower than the reservation value) and leaves the market or does not buy anything. An uninformed buyer chooses randomly, with equal probabilities, one seller and then compares the posted price with his reservation value. If the reservation value is higher than the posted price, the buyer gets one unit of the product and leaves the market; otherwise, he does not buy the product and, without checking the price of the other seller, he leaves the market. ${ }^{9}$

The game is one-shot. There is no repetition. Search is not possible. ${ }^{10}$

The model is symmetric because the probability that an uninformed buyer comes to one of the sellers equals the probability he comes to the other. From a seller's perspective, there is a fixed probability that a specific buyer comes to her whatever price she posts. It is the probability that the buyer is uninformed and he (randomly, with probability $1 / 2$ ) chooses to come to the seller. The probability that an informed

\footnotetext{
${ }^{8}$ The last, and most complex, model includes also the simpler cases. Due to its complexity, I think it is better to understand the mechanics of simpler models first.

${ }^{9}$ The difference between informed and uninformed buyers is usually their search cost. A general search cost would make the model too complicated to be solvable, so it is assumed that some buyers have a zero search cost and some of them have too high a search cost to perform any search.

${ }^{10}$ It will be shown that the game has a unique equilibrium in mixed strategies, so a finitely repeated game has unique equilibrium with the same properties as the presently analyzed oneround game.
} 
buyer comes to the seller is equal to the probability that the seller posts a price that is lower than her competitor's (and lower than the buyer's reservation value). ${ }^{11}$

This model is similar to Varian's model, with two exceptions: I do not assume perfect competition, and the reservation price is specified by a distribution function rather than by a single value identical for all buyers. Perfect competition, as in Varian's model, can be approximated by zero expected profit in the symmetric model. In the asymmetric model, a zero expected profit equilibrium cannot be reached, and asymmetry rules out perfect competition. Varian's single value reservation price is a degenerate case of the distribution function assumption.

I first show that, as in other similar models, a pure strategy equilibrium does not exist. Thereafter, I derive a mixed strategy equilibrium. All propositions in this paper have a common part of the assumptions that are formulated in the following paragraph.

\section{Common Assumptions}

There is a mass of buyers whose distribution of reservation prices, $\hat{D}(\cdot)$, generates a profit function with a single finite local maximum (monopoly price and profit). For notation simplicity, denote $D(p)=1-\hat{D}(p)$. Sellers produce identical units of a good at no cost. Buyers are either informed or uninformed about the prices posted by sellers.

\section{Proposition 1}

Suppose the Common Assumptions hold, and there are two sellers. Then no pure-strategy equilibrium exists when the probability that a seller sells the good at a higher price than a competitor is positive, and there are some informed buyers on the market.

\section{Proof}

Assume the sellers post prices $p_{1}$ and $p_{2}$. . If the prices are unequal, I can, without loss of generality, assume $p_{1}<p_{2} \leq p_{M}$, where $p_{M}$ is the monopoly price (by the

\footnotetext{
${ }^{11}$ In the set-up with a continuum of buyers, both sellers have a share of buyers secured, and they compete on price for the remaining buyers.
} 
definition of a monopoly price, no seller chooses a price bigger than the monopoly price, although they generally can). Seller 1 can increase the expected profit by marginally increasing her price. If $0<p_{1}=p_{2} a$ any seller can increase the expected profit by decreasing her price. The case of $0=p_{1}<p_{2}$ cannot be an equilibrium either because the expected profit is zero, and both sellers can earn strictly positive expected profit by posting $p_{M}$ or, in fact, any positive price within the reservation price distribution support.

The logic behind the mixed-strategy equilibrium results from an optimal weighting of two considerations: making money on volume and competing with the other seller for informed buyers through a low price on the one hand and profiting from a higher price on uninformed buyers on the other. The resulting equilibrium is derived from the distribution function of the buyer's reservation price.

\section{Proposition 2}

Suppose the Common Assumptions hold. Assume that there are two sellers, and the probability that a buyer is uninformed (chooses randomly between the sellers) is $0<\alpha<1 ;^{12}$ he is informed and comes to the seller with the best price.

Then there is a unique (symmetric) mixed-strategy equilibrium with a pricemixing cumulative distribution function (cdf):

$$
\begin{aligned}
\beta(p) & =0, \quad p \leq a, \\
& =\frac{1-\alpha / 2}{1-\alpha}\left(1-\frac{\alpha}{2-\alpha} \frac{M}{p D(p)}\right), \quad p \in[a, b], \\
& =1, \quad p \geq b,
\end{aligned}
$$

where $M$ is the monopoly profit:

$$
M=\max _{q} q D(q)
$$

\footnotetext{
${ }^{12}$ For example, each seller has 'in expectation' secured by $\alpha / 2$ fraction of the market, i.e. the seller sells on average to this amount of buyers. Of course, the offered price must be smaller than the buyer's reservation price for the seller to be able to sell the product to him.
} 
$a$ solves the implicit equation

$$
a D(a)=\frac{\alpha}{2-\alpha} M
$$

and $b=p_{M}=\operatorname{argmax}_{q} \alpha q D(q)$ is the monopoly price.

The expected profit is $\frac{\alpha}{2} \max _{q} q D(q)$, i.e. the profit a seller would secure by setting a monopoly price and selling to 'her' at a fraction of the market.

\section{Proof}

The beginning of the proof is standard, similar to the proofs done by, for example, Varian (1980) or Baye and De Vries (1992). We find the equilibrium mixing strategy represented by a distribution function of price choice. By the definition of mixed-strategy equilibrium a the distribution function makes the competitor indifferent between price choices over a specified interval (the support of the mixing function).

Let $\beta_{i}$ be the mixed strategy distribution function of seller $i, i=1,2$ (I assume that even an asymmetric distribution may exist though I will show later that the distribution function $\beta()$ is unique and therefore, the symmetric equilibrium is unique). Assume first that the support of the distribution function is an interval $\left(a_{i}, b_{i}\right) .{ }^{13}$ The lower bounds of the supports of both $\beta_{i}$ must be identical because setting a lower $a_{i}<a$ would be a mistake, increasing it by half of the difference $\left(a_{-i}-a_{i}\right)$ would increase the profit due to the single local maximum of the profit function property (the probability of winning informed buyers would be 1 in both cases, and the profit would be higher when the price is set to $\left.\left(a_{-i}-a_{i}\right) / 2\right)$.

\footnotetext{
${ }^{13}$ The interval is open, i.e. the probability that a player chooses a price equal to $a$ or $b$ is zero. It is shown later that there are no mass points of the distributions.
} 
The expected profit function can be expressed as

$$
\begin{aligned}
\pi_{i}(p) & =\frac{\alpha}{2} p D(p)+(1-\alpha) p D(p)\left(1-\beta_{-i}(p)\right) \\
& =\left(1-\frac{\alpha}{2}\right)\left(\frac{\alpha / 2}{1-\alpha / 2} p D(p)+\frac{1-\alpha}{1-\alpha / 2} p D(p)\left(1-\beta_{-i}(p)\right)\right) \\
& =\left(1-\frac{\alpha}{2}\right) p D(p)\left(1-\frac{1-\alpha}{1-\alpha / 2} \beta_{-i}(p)\right) \\
& =\left(1-\frac{\alpha}{2}\right) p D(p)\left(1-c \beta_{-i}(p)\right),
\end{aligned}
$$

where $c=\frac{1-\alpha}{1-\alpha / 2}$.

From this point on, I simplify the notation of the profit and the distribution function indices: $\pi()=\pi_{i}()$ and $\beta()=\beta_{-i}()$.

For the competitor to be indifferent between choosing prices $p_{1}, p_{2} \in(a, b)$, the expected profits related to the two prices must be equal.

$$
\begin{aligned}
\pi\left(p_{1}\right) & =\pi\left(p_{2}\right) \\
p_{1} D\left(p_{1}\right)\left(1-c \beta\left(p_{1}\right)\right) & =p_{2} D\left(p_{2}\right)\left(1-c \beta\left(p_{2}\right)\right) \\
\frac{1-c \beta\left(p_{1}\right)}{1-c \beta\left(p_{2}\right)} & =\frac{p_{2} D\left(p_{2}\right)}{p_{1} D\left(p_{1}\right)} .
\end{aligned}
$$

Since $\beta(a)=0$, I can rewrite the equation to

$$
1-c \beta\left(p_{1}\right)=\frac{a D(a)}{p_{1} D\left(p_{1}\right)}
$$

that gives me the mixed strategy function formula

$$
\beta(p)=\frac{1}{c}-\frac{a D(a)}{c p D(p)}
$$

The expected profit is equal to $\pi=(1-\alpha / 2) a D(a)$ because setting the price equal to the lower bound $a$ we would sell the good to all searchers almost sure ${ }^{14}$ and the expected profit of all choices of price must be equal. From the equality

\footnotetext{
${ }^{14}$ As the support of the mixed strategy is open, $a$ is never chosen. A completely correct proof would use limits and is straightforward.
} 
and the profit when the monopoly price is chosen $(\max \alpha / 2 p D(p))$, it is possible to derive the following inequality: ${ }^{15}$

$$
\pi=(1-\alpha / 2) a D(a) \geq \max \alpha / 2 p D(p) .
$$

I assume for now that the mixing function $\beta(b)$ is continuous everywhere, and that there are no "gaps", i.e. the mixing function is increasing. The discontinuity case and "gaps" are discussed at the end of the proof. The continuity and equality $\beta(b)=1$ imply, using formula $(2.1)$,

$$
1-c=\frac{a D(a)}{b D(b)}
$$

The upper bound of support $b$ must be lower than or equal to the monopoly price $^{16}$ and $a$ must be strictly smaller than the monopoly price. That gives me the implicit inequality:

$$
a D(a) \leq(1-c) \max p D(p), a<\operatorname{argmax} p D(p)
$$

and substituting for $a D(a)$ in the equation $\pi=(1-\alpha / 2) a D(a)$ derived above, I get the formula for maximum expected profit:

$$
\pi \leq(1-\alpha / 2)(1-c) \max p D(p) .
$$

Substituting for $c$, I obtain

$$
\pi \leq \alpha / 2 \max p D(p) .
$$

\footnotetext{
${ }^{15}$ When the monopoly price is chosen, the seller sells only to uninformed customers. Therefore the expected profit $\pi$ must be at least as big as if the monopoly price is chosen.

${ }^{16} \mathrm{~A}$ formal proof of the equality $b=p_{M}$ follows. Informally, if $b<p_{M}$, when choosing the price $b$ the probability of selling to informed buyers is zero; therefore, $\pi(b)<\pi\left(p_{M}\right)$, which contradicts the equilibrium assumptions.
} 
Using inequality (2.2), the equality holds, i.e.

$$
\pi=(1-\alpha / 2) a D(a)=\alpha / 2 \max p D(p) .
$$

The lower bound of the mixing interval $a$ is the solution of the implicit equation

$$
a D(a)=\frac{\alpha}{2-\alpha} \max p D(p),{ }^{17}
$$

and using equation (2.3), the upper bound $b$ is equal to the monopoly price.

Gaps in $\beta$

A gap in a distribution is defined to be an interval where the mixed strategy function is constant (different from 0 and 1). We will show there are no gaps in the functions $\beta_{i}$. Assume the mixing functions of the two competitors are not equal, $\beta_{1} \neq \beta_{2}$. Assume that $\beta_{1}$ is constant in the interval $(c, d) \subset(a, b)$. If player 2 chooses a price in this interval with a positive probability, she would make a mistake. She would increase her expected profit when she moves the whole mass from the interval $(c, d)$ to the point $d$. Therefore, gaps must be symmetric if there are any.

Assume there is a symmetric gap $(c, d) \subset(a, b)$, and it is the lowest one (if there are many gaps $\left(c_{i}, d_{i}\right), c$ and $d$ are the smallest limits). Note that $c>a \geq 0$ because $a$ is the lower bound of the mixed strategy function. $\epsilon>0$ exists such that a player benefits from moving the probability from the interval $(c-\epsilon, c)$ to the point $d$. For $\epsilon$, it suffices to satisfy the equation $\beta(c-\epsilon) d>\beta(c) c$, i.e. the benefits outweigh the losses. Thus, there are no gaps in the distribution.

\section{Discontinuity of $\beta_{i}$}

The discontinuity of $\beta_{i}$ means that there are atoms in the mixed strategy cumulative distribution function, or that a particular price is chosen with a strictly positive probability. I will show that such a price does not exist in equilibrium.

\footnotetext{
${ }^{17}$ Again, solution existence and uniqueness follow from the single local maximum property of the profit function.
} 
First, note that there can be only a symmetric equilibrium. We have shown before that the lower bounds of the mixing intervals are identical for all sellers. The formula for the mixing function $\beta()$ is dependent only on the share of uninformed buyers $\alpha$, mixing interval lower bound $a$ and the distribution function of the reservation prices. Therefore, the distribution function must be identical for all sellers.

This implies that, if there were a mass point, it would be identical for both players. In that case, an undercutting procedure would start - a move of the mass point to a slightly smaller price would be beneficial (again, recall that $a>0$ ). Therefore, the mixed strategy cumulative distribution functions $\beta_{i}$ are continuous.

The solution can be evaluated even in the extreme case of $\alpha=1$ when each seller owns half of the market. In that case, the mixing interval shrinks to one point $a=b=p_{\text {monopoly }}$. In the other extreme, $\alpha=0$, when all buyers are informed, and the lower bound of the interval as well as the expected profit are equal to 0 , the upper bound should be also 0. Therefore, even the limits in extreme cases are in line with the existing theory.

The above model has been developed for price competition between two sellers. Naturally, we may ask what happens when a higher number of sellers enters the market. I keep the basic set-up unchanged and solve it for an arbitrary number of $N$ competing sellers. The characteristics of the buyers remain the same. The probability of a buyer choosing a seller randomly (and not searching for the lowest price) is $\alpha$. It means that every seller has secured a $\alpha / N$ share of the market. The model equilibrium is characterized in the following proposition. 


\section{Proposition 3}

Assume that the Common Assumptions hold, and there are $N$ sellers. Assume that the probability a buyer is uninformed and chooses randomly between the sellers is $0<\alpha<1$, and the probability a buyer chooses one particular seller is identical for all sellers and is equal to $\alpha / N$. The probability that a buyer is informed and knows the posted prices of all sellers in advance is therefore $1-\alpha$.

Then, there is no pure-strategy equilibrium, and a unique symmetric mixedstrategy equilibrium with price-mixing cdf is

$$
\begin{aligned}
\beta(p) & =0, \quad p \leq a \\
& =1-\left(\frac{\alpha}{N(1-\alpha)} \frac{M}{p D(p)}-\frac{\alpha}{N(1-\alpha)}\right)^{\frac{1}{N-1}}, \quad p \in[a, b] \\
& =1, \quad p \geq b,
\end{aligned}
$$

where $M$ is the monopoly profit, $b=p_{M}$ the monopoly price, and $a$ solves the implicit equation $a D(a)=\frac{\alpha}{N-(N-1) \alpha} M$.

The expected profit is $\frac{\alpha}{N} \max _{q} q D(q)$, i.e. the profit a seller would secure setting a monopoly price and selling to 'her' fraction of market.

\section{Proof}

The proof of the non-existence of the pure-strategy equilibrium is analogous to the proof of Proposition 1.

The logic behind the derivation of the mixed-strategy equilibrium copies the proof of Proposition 2; thus I indicate here just the key points of the proof.

I assume the symmetry of the equilibrium. Let $\beta(p)$ label the mixed strategy cdf and the interval $(a, b)$ its support. The associated cdf of minimum price set by $N-1$ competitors is $B(p)=1-(1-\beta(p))^{N-1}$. I can express the expected profit as

$$
\pi(p)=\frac{\alpha}{N} p+(1-\alpha) p(1-B(p))
$$

Using the argument that $\pi\left(p_{1}\right)=\pi\left(p_{2}\right), \quad \forall p_{1}, p_{2} \in(a, b)$ I get the counterpart 
of the equation (2.1):

$$
1-c B(p)=\frac{a D(a)}{p D(p)}
$$

where $c=\frac{1-\alpha}{1-\frac{N-1}{N} \alpha}$. Substituting for $B(\cdot)$ and rearranging the equation I obtain the formula for the mixing function:

$$
\beta(p)=1-\left(\frac{1}{c} \frac{a D(a)}{p D(p)}-\frac{1-c}{c}\right)^{\frac{1}{N-1}} .
$$

Setting the price at the lower bound of the interval $(a, b)$, the seller sells to all informed buyers almost sure, and I have to have at least the profit of selling only to uninformed buyers at the monopoly price, so $^{18}$

$$
\pi=\left(1-\frac{N-1}{N} \alpha\right) a D(a) \geq \max \frac{\alpha}{N} q D(q) .
$$

Equation (2.4) expressed for $p=b$ gives me the inequality

$$
a D(a)=(1-c) b D(b) \leq(1-c) \max q D(q), a<\operatorname{argmax} q D(q) .
$$

Together with (2.5) and substituting for $c$ I get

$$
a D(a)=\frac{\alpha}{N-(N-1) \alpha} \max q D(q)
$$

and

$$
\pi=\frac{\alpha}{N} \max q D(q)
$$

Substituting for $c$ and $a D(a)$ in the equation defining $\beta(p)$, I obtain the final form of the mixing function.

The proof of the continuity and strict monotonicity (no gaps property) of the distribution function $\beta(\cdot)$ is completely analogous to the proof of Proposition 2.

\footnotetext{
${ }^{18} \mathrm{As}$ in the previous proof, the precise derivation of the first equality is the limit $\pi=$ (Probability of winning $)^{*}$ (amount won), where the first term approaches 1 when $p \rightarrow a$, and the second term approaches $\max \frac{\alpha}{N} q D(q)$.
} 


\section{Uniqueness of the upper bound}

If there were two different upper bounds $b_{1} \neq b_{2}$, then there would need to be a gap or a mass point in the mixing function, which is ruled out. If $b<p_{M}$, then the expected profit would need to be smaller than $\alpha / N p_{M}$; therefore, sellers would tend to choose $p=p_{M}$, and the upper bound is therefore unique.

\section{Uniqueness of the lower bound}

Assume sellers choose different lower bounds $a_{1} \leq a_{2} \leq a_{3} \leq \ldots$ The lowest of all bounds has to be equal to $a_{1}=a$. To set a lower bound is unprofitable, and someone has to choose it because the equilibrium profit is equal to the profit gained from choosing $a$. Also, at least one other player has to have the lower bound equal to $a$; otherwise, seller 1 would tend to increase her lower bound. Assume that $M<N$ players have the lower bound of the mixing interval equal to $a$ and the seller $M+1$ has the lower bound equal to $\hat{a}>a$. When I set the number of sellers $N$ to be a parameter of the function $\beta=\beta(p, N)$, then the mixing function of the first $M$ sellers $\beta_{1}$ in the first part of the interval would be $\beta_{1}(p)=\beta(p, M), p \in(a, \hat{a})$. As $\frac{\partial}{\partial N} \beta(p, N)<0$, the inequality $\beta_{1}(p)<\beta(p, M), p \in(a, \hat{a})$ holds, and the player would get a higher-than-equilibrium profit choosing a price from the interval $(a, \hat{a})$ that is, however, outside her mixing interval. Therefore, her mixing interval lower bound has to be equal to $a$, and the equilibrium is unique.

Because the bounds of the supports of the mixed strategy cumulative distribution functions are equal for all sellers, there are no gaps or mass points, and since the mixed strategies follow the above derived formulae, the equilibrium is unique.

Equilibrium prices can be influenced by a variation of two basic parameters, the fraction of informed buyers $1-\alpha$ and the number of competitors $N$. The increasing number of informed buyers (or the increasing probability of the buyer being informed) directly lowers the (expected) profit of sellers and changes the division of the surplus in favor of the buyers. ${ }^{19}$ The lower bound of the mixing interval

\footnotetext{
${ }^{19}$ I assume there are no search costs in the model. A natural extension of the model would be the introduction of the endogenous choice of the fractions of informed buyers. In such a model,
} 
decreases towards zero faster than linearly as the fraction of searchers increases. The shape of the mixing function itself stretches out proportionally over the mixing interval.

The effect of increased competition differs from the effect of the increased proportion of informed buyers. The expected buyers' and sellers' surpluses do not change in the case of increased competition, only the sellers' surplus is spread across a larger number of sellers. The lower bound of the mixing interval (the interval of prices that can be posted by sellers in equilibrium) is inversely proportional to the number of sellers. The shape of the mixing function thus changes as the number of competitors increases; the probability of choosing a smaller price close to the lower bound decreases and the probability of choosing a price close to the monopoly price increases. There are two countervailing phenomena that influence the expected minimum price on the market: a decreased lower bound of the mixing interval that decreases the expected minimum price on the market and the shifted weight of the mixing function towards the monopoly price, which increases the expected minimum price. I now analyze the minimum in more detail.

Keeping the notation of Proposition 3, the expected minimum price for $N$ sellers is $^{20}$

$$
E p_{\text {min }}=a+\int_{a}^{b}\left(\frac{\alpha}{N(1-\alpha)}\left(\frac{M}{p D(p)}-1\right)\right)^{\frac{N}{N-1}} d p .
$$

The effect of increased competition can be determined from the derivative of the expected minimum with respect to $N$ :

$$
\frac{d E p_{\min }}{d N}=\int_{a}^{b} \frac{d}{d N}\left(\frac{\alpha}{N(1-\alpha)}\left(\frac{M}{p D(p)}-1\right)\right)^{\frac{N}{N-1}} d p
$$

The expression in the outer brackets gets a value of 1 for $p=a$ and a value of 0 for $p=b$; thus, its values in the integration limits belong to the interval $(0,1)$. The I would observe not only a transfer of surplus from sellers to buyers, but also a decrease of total surplus due to increased search costs.

${ }^{20}$ The expected minimum price is equal to $\int_{a}^{b} p d \hat{B}(p)$, where $\hat{B}(p)=1-(1-\beta(p))^{N}$. Integrating by parts, I get the formula for the expected minimum price. 
exponent is always bigger than 1 , and it is decreasing in $N$ so the whole function is decreasing in $N$, and the derivative is always negative (the derivative exists). It implies that the expected minimum price decreases with increasing competition.

This result implies that informed buyers benefit from increased competition, sellers maintain the expected sum of profits unchanged as competition increases, and uninformed buyers fully pay the benefit of informed buyers.

To summarize, an increased number of informed buyers depletes the profit of sellers. An increased number of sellers leads to the total volume of profits being split across a larger number of competing sellers, while the absolute value remains unchanged. Informed buyers benefit from increased competition while the uninformed lose.

\section{Asymmetric model}

I now add asymmetry to the model. In the symmetric set-up presented so far, uninformed buyers randomly selected a seller they decided to visit. Randomness was symmetric with respect to sellers: The probability that a specific uninformed buyer would visit a specific seller was equal across all sellers and buyers. In an asymmetric set-up, the probability that a buyer visits a specific seller may differ across sellers.

An asymmetric set-up can capture the behavior of uninformed buyers that for various reasons may not be randomizing. A real-life situation captured by such a model would be brand sensitivity (or even loyalty). A fraction $\alpha_{1}$ of potential buyers prefers a particular seller, another fraction $\alpha_{2}$ of buyers prefers a different seller, and the remaining buyers are searchers. If we randomly select a buyer in this brand sensitivity model, the probability that he prefers the first seller is $\alpha_{1}$, and the probability that he prefers the second seller is $\alpha_{2}$. Thus, in the brand sensitivity model, I can think of buyers that prefer a seller as uninformed buyers and of searchers as informed buyers. ${ }^{21}$

\footnotetext{
${ }^{21}$ The model can be used in the field of promotion if I assume brand sensitivity, or loyalty, can be endogenized assuming it can be changed by sellers' investments.
} 
The formulation of the model remains essentially the same as in the symmetric case with the exception that uninformed buyers are positioned asymmetrically. For every seller, I specify her share of buyers who are not informed of the lowest price and/or who do not go directly to other sellers. These shares may be different for every seller. ${ }^{22}$ As in the previous section, I first analyze the simplest possible model - the competition of two sellers.

\section{Proposition 4}

Assume that the Common Assumptions hold, and there are two sellers. Assume that the probability a buyer is uninformed and visits the first seller is $\alpha_{1}$, and the probability the buyer is uninformed and visits the second seller is $\alpha_{2}{ }^{23}$ Assume, without loss of generality, that $\alpha_{1}>\alpha_{2}$. The remaining probability $1-\alpha_{1}-\alpha_{2}$ represents informed buyers.

Then there is a unique mixed-strategy equilibrium with price-mixing cdf of the first seller: ${ }^{24}$

$$
\begin{aligned}
\beta_{1}(p) & =0, \quad p<a \\
& =\frac{1-\alpha_{1}}{1-\alpha_{1}-\alpha_{2}}\left(1-\frac{a D(a)}{p D(p)}\right), \quad p \in\left[a, p_{M}\right) \\
& =1, \quad p \geq p_{M}
\end{aligned}
$$

and the price-mixing cdf of the second seller

$$
\begin{aligned}
\beta_{2}(p) & =0, \quad p<a \\
& =\frac{1-\alpha_{2}}{1-\alpha_{1}-\alpha_{2}}\left(1-\frac{a D(a)}{p D(p)}\right), \quad p \in\left[a, p_{M}\right] \\
& =1, \quad p \geq p_{M}
\end{aligned}
$$

\footnotetext{
${ }^{22}$ Or, in other words, I specify the probabilities that a specific buyer visits each seller even if the seller does not post the lowest price on the market.

${ }^{23}$ This means the first seller has secured a fraction $\alpha_{1}$ of the market and the second seller has secured $\alpha_{2}$ of the market.

${ }^{24}$ Note there is a positive probability that seller 1 chooses the monopoly price, and the mixed strategy distribution function has a mass point in $p_{M}$. The result and the mathematic properties of the equilibrium are discussed between this Proposition and the Proof.
} 
where $M$ is the monopoly profit, $p_{M}$ the monopoly price, and $a$ solves the implicit equation

$$
a D(a)=\frac{\alpha_{1}}{1-\alpha_{2}} M
$$

The expected profit of the stronger seller (the seller with a higher share of uninformed buyers) is $\alpha_{1} \max _{q} q D(q)$, and the profit of the weaker seller is $\alpha_{1} \max _{q} q D(q)-$ $\left(\alpha_{1}-\alpha_{2}\right) a D(a)$.

In equilibrium an interesting behavior can be seen close to the monopoly price. On the graph below, the equilibrium of the set-up $\alpha_{1}=0.2, \quad \alpha_{2}=0.1$, and $D(p)=$ $1-p$, (uniformly distributed reservation values of buyers over the interval $(0,1))$ is plotted. The monopoly price is $1 / 4$, and the lower bound of the mixed strategies is approximately 0.06 .

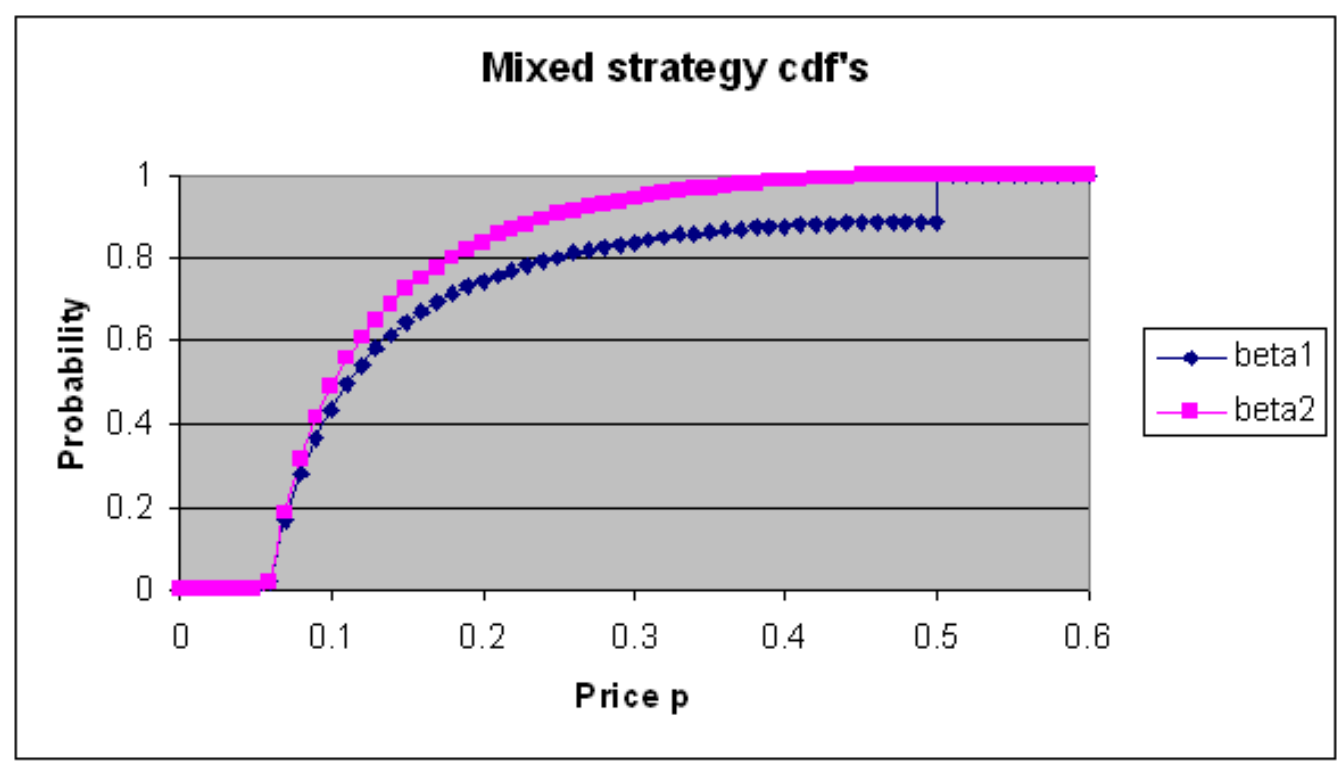

We can see that there is a probability of more than $10 \%$ that the stronger seller sets the monopoly price. The behavior of the weaker and the stronger seller just below the monopoly price is clearly visible there. The weaker player sets a price from any interval $\left(p_{M}-\epsilon, p_{M}\right), \quad \epsilon>0$ with positive probability, but the price $p_{M}$ is never selected. This behavior prevents the stronger player from shifting the probability mass to $p_{M}$ so that a gap would appear under the monopoly price. On the contrary, the stronger player selects the prices below the monopoly price with probabilities much lower than 1 so that the weaker player is motivated to assign 
some probability to these prices. The mass point in the monopoly price is formed by the "remaining" probability.

Mathematically, this situation is described by the supports of the associated probability functions. The support of the weaker seller is $\left(a, p_{M}\right)$, i.e. any price can be selected but $p_{M}$. The support of the stronger seller is $\left(a, p_{M}\right]$, i.e. any price can be selected including $p_{M}$, which is selected with a positive probability.

\section{Proof of Proposition 4}

The proof follows the same logic as the proofs of Propositions 2 and 3. First, I develop the expected profit function of the two competing sellers. In the previous section, the expected profit functions coincided for both sellers, and the equilibrium strategies were equivalent. Because the set-up is asymmetric, the solution cannot be symmetric either. I have to develop profit functions and strategies for each seller individually. I label the first seller's expected profit function and strategy (the cdf of the price choice) $\pi_{1}(p)$ and $\beta_{1}(p)$, respectively, and $\pi_{2}(p)$ and $\beta_{2}(p)$ analogously label the corresponding variables for the second seller. The expected profit functions of the two sellers are:

$$
\begin{aligned}
\pi_{1}(p) & =\alpha_{1} p D(p)+\left(1-\left(\alpha_{1}+\alpha_{2}\right)\right) p D(p)\left(1-\beta_{2}(p)\right) \\
& =\left(1-\alpha_{2}\right) p D(p)\left(\frac{\alpha_{1}}{1-\alpha_{2}}+\frac{1-\alpha_{1}-\alpha_{2}}{1-\alpha_{2}}-\frac{1-\alpha_{1}-\alpha_{2}}{1-\alpha_{2}} \beta_{2}(p)\right. \\
& =\left(1-\alpha_{2}\right) p D(p)\left(1-c_{1} \beta_{2}(p)\right), \\
\pi_{2}(p) & =\left(1-\alpha_{1}\right) p D(p)\left(1-c_{2} \beta_{1}(p)\right)
\end{aligned}
$$

where $c_{1}=\frac{1-\alpha_{1}-\alpha_{2}}{1-\alpha_{2}}$ and $c_{2}=\frac{1-\alpha_{1}-\alpha_{2}}{1-\alpha_{1}}$.

I continue to evaluate the strategy of the 'weaker' second seller (the seller with a smaller amount of uninformed buyers). The formulae relevant for the first seller apply analogously for a couple of the following steps.

The first seller has to be indifferent between prices in the mixing interval, there- 
fore

$$
\begin{aligned}
\pi_{1}\left(p_{1}\right) & =\pi_{1}\left(p_{2}\right) \\
p_{1} D\left(p_{1}\right)\left(1-c_{1} \beta_{2}\left(p_{1}\right)\right) & =p_{2} D\left(p_{2}\right)\left(1-c_{1} \beta_{2}\left(p_{2}\right)\right) \\
\frac{1-c_{1} \beta_{2}\left(p_{1}\right)}{1-c_{1} \beta_{2}\left(p_{2}\right)} & =\frac{p_{2} D\left(p_{2}\right)}{p_{1} D\left(p_{1}\right)} .
\end{aligned}
$$

I label the lower bounds for the first and second player $a_{1}$ and $a_{2}$ and the upper bounds $b_{1}$ and $b_{2}$. Note that I do not assume there is not a mass point in $b_{i}$. In fact, I will show that seller 1 chooses price $b_{1}$ with a positive probability. I evaluate the previous formula at $p_{1}=b_{2}, p_{2}=a_{2}$ and find $\left(1-c_{1}\right) b_{2} D\left(b_{2}\right)=a_{2} D\left(a_{2}\right)$ or

$$
\frac{\alpha_{1}}{1-\alpha_{2}} b_{2} D\left(b_{2}\right)=a_{2} D\left(a_{2}\right)
$$

If the second seller sets the price $p=a_{2}{ }^{25}$ and wins the informed buyers, she gets a profit of at least $\alpha_{2} M$, where $M$ denotes the monopoly profit with respect to the demand function $D(\cdot)$. Otherwise she would prefer to sell to her fraction of the market $\alpha_{2}$ at the monopoly price $p_{M}$. This argument can be expressed as the equality $\left(1-\alpha_{1}\right) a_{2} D\left(a_{2}\right) \geq \alpha_{2} M$. Rearranging terms, I get $\frac{\left(1-\alpha_{1}\right) \alpha_{1}}{\left(1-\alpha_{2}\right) \alpha_{2}} b_{2} D\left(b_{2}\right) \geq M$. Using an analogical procedure, I get $\frac{\left(1-\alpha_{2}\right) \alpha_{2}}{\left(1-\alpha_{1}\right) \alpha_{1}} b_{1} D\left(b_{1}\right) \geq M$. Note that $b_{1}=b_{2}$. If not, there would be a gap between $b_{1}$ and $b_{2}$, and subsequently, it would be beneficial to switch some mass of the distribution function of the strategy from the lower bound of the gap to the upper bound of the gap for one player. Thus, in equilibrium, $b_{1}=b_{2}=b$. The previous two equations imply that $b D(b)=M$. Then, I can express the lower bounds as

$$
a_{2} D\left(a_{2}\right)=\frac{\alpha_{1}}{1-\alpha_{2}} M
$$

\footnotetext{
${ }^{25}$ The seller chooses this price, in fact, with zero probability; therefore, it would be an invalid argument. I use it to simplify the full argumentation of setting price $p=a_{2}+\epsilon$ and evaluating the limit $\epsilon \rightarrow 0$.
} 
and

$$
a_{1} D\left(a_{1}\right)=\frac{\alpha_{2}}{1-\alpha_{1}} M
$$

However, I know that $a_{1}=a_{2}$ otherwise the strategy of one seller would be irrational. Namely, as $\alpha_{1}>\alpha_{2}$ and thus $a_{2}>a_{1}$, the first player would prefer to move the mass of the function $\beta_{1}(\cdot)$ from the interval $\left(a_{1}, a_{2}\right)$ to the point $a_{2}-\epsilon$ and increase the expected profit. In fact, the first seller would not be willing to select a price lower than $a_{2}$ - even if the probability of winning is 1 , she would not get more than $\alpha_{1} M$ in expected value. Therefore, I let the second player's strategy remain the same as derived above and derive the first player's strategy that satisfies the equality $a_{1}=a_{2}$ and the requirement that the second player is indifferent between choosing any price from the interval $\left[a_{2}, b_{2}\right]$. As before,

$$
\begin{aligned}
\pi_{2}\left(p_{1}\right) & =\pi_{2}\left(p_{2}\right) \\
p_{1} D\left(p_{1}\right)\left(1-c_{2} \beta_{1}\left(p_{1}\right)\right) & =p_{2} D\left(p_{2}\right)\left(1-c_{2} \beta_{1}\left(p_{2}\right)\right) \\
\frac{1-c_{2} \beta_{1}\left(p_{1}\right)}{1-c_{2} \beta_{1}\left(p_{2}\right)} & =\frac{p_{2} D\left(p_{2}\right)}{p_{1} D\left(p_{1}\right)} .
\end{aligned}
$$

As defined earlier, $\beta_{1}\left(a_{2}\right)=0$. Setting $p_{2}=a_{2}$ and rearranging, I get

$$
\beta_{1}(p)=\frac{1}{c_{2}}\left(1-\frac{a_{2} D\left(a_{2}\right)}{p D(p)}\right)
$$

Because the following equalities hold, ${ }^{26} \beta_{1}\left(p_{M}-\right)=\frac{1}{c_{2}}\left(1-\frac{a_{2} D\left(a_{2}\right)}{p_{M} D\left(p_{M}\right)}\right)<1$ and $\beta_{1}\left(p_{M}\right)=1$, the stronger player sets the monopoly price with a positive probability. This function leaves the second player indifferent between prices within the interval $\left[a_{2}, p_{M}\right)$, and the above derived strategy leaves the first player indifferent between prices within the interval $\left[a_{2}, p_{M}\right]$.

Therefore, the system

\footnotetext{
${ }^{26}$ The notation $\beta_{1}\left(p_{M^{-}}\right)$assigns the left limit of the function $\beta_{1}$ in the point $p_{M}$.
} 


$$
\begin{aligned}
& \beta_{2}(p)=\frac{1}{c_{1}}\left(1-\frac{a D(a)}{p D(p)}\right), \quad p \in\left[a, p_{M}\right] \\
& \beta_{1}(p)=\frac{1}{c_{2}}\left(1-\frac{a D(a)}{p D(p)}\right), \quad p \in\left[a, p_{M}\right) \\
& \beta_{1}\left(p_{M}\right)=1 \\
& a D(a)=\frac{\alpha_{1}}{1-\alpha_{2}}
\end{aligned}
$$

constitutes the equilibrium.

\section{Uniqueness}

I have derived a formula for a mixing function that leaves the opponent indifferent between choosing prices from the interval $\left[a_{2}, p_{M}\right)$ in the previous part of the proof. This formula defines a unique solution if:

1. the lower and upper bounds of the support are unique and

2. the functions are strictly increasing in the support. ${ }^{27}$

The uniqueness of the upper bound has been shown before. It needs to be shown that the functions have to be strictly increasing in the support (or that there are no gaps in the support) and that the lower bound is unique.

There are no gaps in the distribution functions $\beta_{i}$

If there is a gap in a distribution function there must be the same in the second one; otherwise, the second seller would not behave rationally. As in the proof of Proposition 2, it is possible to show that shifting some mass from the lower bound of the gap to the upper bound, the seller would benefit; therefore, there can be no gap in the distribution function.

There are no mass points except the one in $p_{M}$ for $\beta_{1}$

The situation of a symmetric mass point, i.e. the situation where both $\beta_{1}$ and $\beta_{2}$ have a mass point for the same price, would initiate an undercutting procedure.

\footnotetext{
${ }^{27}$ Theoretically, if my opponent never chooses prices from a specific interval I do not need to 'make him indifferent' in that interval and I would not need to follow the prescribed formula. In that case there would exist infinitely many strategies.
} 
Therefore, there can be no symmetric mass point. If there is a mass point in $x \in\left(a, p_{M}\right)$ in the function $\beta_{i}$ and $\beta_{-i}<1$, then it it easy to show that shifting the mass of the probability function $\beta_{-i}$ from the interval $\left(x, x+\epsilon_{1}\right)$ to the point $x-\epsilon_{2}$ for some $\epsilon_{1}, \epsilon_{2}>0$ would increase the expected profit of the seller $-i$. Therefore, there can be no mass point in any of the two distribution functions with the mentioned exception.

\section{The lower bound a is unique}

As the functions $\beta_{i}$ must be increasing in $\left(a, p_{M}\right)$ and there are no mass points, the functions can be represented by the formulae derived above for a given $a$. If I assume that $\hat{a}<\frac{\alpha_{1}}{1-\alpha_{2}}$, then the stronger seller has no incentive to set a positive probability to the prices in the interval $\left(\hat{a}, \frac{\alpha_{1}}{1-\alpha_{2}}\right)$, which violates the no gaps property. If, in contrast, $\hat{a}>\frac{\alpha_{1}}{1-\alpha_{2}}$, the values of mixing functions at monopoly prices are $\beta_{i}\left(p_{M}\right)<1$ for both functions, which violates the no mass points property. Therefore, the lower bound $a=\frac{\alpha_{1}}{1-\alpha_{2}}$ is unique.

I have found an interesting result. In an asymmetric duopoly, the weaker seller (the one with the smaller share of uninformed buyers) gains from the position of the stronger seller. If the stronger seller's market share increases, the weaker seller's expected profit rises as fast as the stronger seller's even though the weaker seller does not invest in capturing a larger share of the market. Also, it is much more probable that the weaker seller sets a lower price than the stronger one and wins the searchers. The wider the gap between the weaker and the stronger seller, i.e. the bigger difference between the market shares of the two sellers, the higher the probability that the stronger seller sets the monopoly price and sells to 'her' market share.

The above-mentioned facts have consequences for buyers. If we start from a symmetric position and let one seller capture a larger market share, then the expected profit of the sellers increases as if both players' market shares increase in the same way. The increase of the sellers' profit is not paid by the buyers who caused the market share to increase but in the majority by previously uninformed 
buyers and partially by informed buyers. When, in contrast, I start from an asymmetric position and the gap between the sellers' market shares moves towards the symmetric position so that more buyers become uninformed, the expected profit of the sellers does not change. The buyers who switch from informed to uninformed necessarily lose (recall I do not have search cost in the model), therefore informed buyers benefit from the increased market share of the weaker seller.

The last step is to develop the most general model. It is an asymmetric model of competition among $N$ sellers when every individual seller has secured her own market share $\alpha_{i}$, or the probability that a specific uninformed buyer visits her. This model, naturally, covers all the already-analyzed specific cases. It will help us understand the logic and nature of the equilibrium.

\section{Proposition 5}

Assume that the Common Assumptions hold, and there are $N$ sellers. Assume that the probability a buyer chooses to visit seller $i$ is $\alpha_{i}{ }^{28}$ The sellers are, without loss of generality, sorted according to ascending market share: $\alpha_{1} \leq \alpha_{2} \leq \cdots \leq \alpha_{N}$. The remaining probability $1-\sum \alpha_{i}$ represents informed buyers.

Then there is a unique mixed-strategy equilibrium, where the price-mixing cdfs $\beta_{i}$ can be expressed $\operatorname{as}^{29}$

$$
\begin{aligned}
\beta_{i}(p) & =0, \quad p \leq a_{i}, \\
& =1-\frac{\prod_{j, a_{j}<p} k_{j}^{\frac{1}{m-1}}}{k_{i}} \quad p \in\left[a_{i}, p_{M}\right), \\
& =1, \quad p \geq p_{M} \\
k_{i} & =\left(1+c_{i}\left(\left(\prod_{j<i}\left(1-\beta_{j}\left(a_{i}\right)\right)-1\right)\right)\right) \frac{a_{i} D\left(a_{i}\right)}{c_{i} p D(p)}-\frac{1-c_{i}}{c_{i}} \\
c_{i} & =\frac{1-\mathcal{A}}{1-\mathcal{A}_{-i}}, \quad \mathcal{A}=\sum \alpha_{i}, \quad \mathcal{A}_{-i}=\mathcal{A}-\alpha_{i}, \\
m & =\max _{l}\left(a_{l}<p\right),
\end{aligned}
$$

\footnotetext{
${ }^{28}$ This means that each seller has "in expectation" secured a fraction $\alpha_{i}$ of the market.

${ }^{29}$ For the weakest seller 1 , the function is continuous; for other sellers, there can be a discontinuity in $p_{M}$, i.e. they can choose the price $p_{M}$ with a positive probability.
} 
where $M$ is the monopoly profit and $p_{M}$ the monopoly price. The lower bound of every distribution function $a_{i}$ is chosen as the solution of the implicit equation valid $\forall i>1$ and for $i=1$ if $\alpha_{1}=\alpha_{2}$

$$
\left(\alpha_{i}+(1-\mathcal{A})\left(\prod_{j<i}\left(1-\beta_{j}\left(a_{i}\right)\right)\right)\right) a_{i} D\left(a_{i}\right)=\alpha_{i} M
$$

where $M$ is the monopoly profit. If $\alpha_{1}<\alpha_{2}$, then $a_{1}=a_{2}$.

The expected profits of sellers are $\alpha_{i} M, \forall i>1$, and $i=1$ if $\alpha_{1}=\alpha_{2}$, i.e. the profit the first seller would secure setting a monopoly price and selling to 'her' fraction of market. If $\alpha_{1}<\alpha_{2}$, then the first seller's expected profit is $\alpha_{2} M-\left(\alpha_{2}-\right.$ $\left.\alpha_{1}\right) a_{2} D\left(a_{2}\right)$, i.e. the profit of the second-weakest seller minus the difference of the profit from the uninformed buyers at the lower bound of the mixing interval.

\section{Proof}

The proof follows the standard line used in the previous proofs. First, the profit function of each seller is defined. I use the fact that each seller has to have identical expected profits for all prices she is willing to set to obtain a system of equations that defines the mixed strategy cumulative distribution functions of all players.

Assume that $\alpha_{1} \leq \alpha_{2} \leq \cdots \leq \alpha_{N}$. Label the respective mixing functions for sellers $i=1, \ldots, N \beta_{i}(p)$ and the supports of the mixing functions $\left(a_{i}, b_{i}\right] .{ }^{30}$ To keep the notation simple, I use the fact that $a_{1} \leq a_{2} \leq \cdots \leq a_{N}$, and will be proven later, and no step in the proof depends on this fact. I denote $\mathcal{A}=\sum_{j=1}^{N} \alpha_{j}$ and $\mathcal{A}_{-i}=\mathcal{A}-\alpha_{i}$.

The expected profit of seller $i$ is her expected profit from uninformed buyers who come directly to her and the expected profit from the searchers if she selects

\footnotetext{
${ }^{30}$ Later I will show that the weakest seller chooses the upper bound with zero probability and others may choose it with a positive probability.
} 
the lowest price on the market.

$$
\begin{aligned}
\pi_{i}(p) & =\alpha_{i} p D(p)+(1-\mathcal{A}) p D(p) \prod_{j \neq i}\left(1-\beta_{j}(p)\right) \\
& =\left(1-\mathcal{A}_{-i}\right) p D(p)\left(1+c_{i}\left(\prod_{j \neq i}\left(1-\beta_{j}(p)\right)-1\right)\right),
\end{aligned}
$$

where $c_{i}=\frac{1-\mathcal{A}}{1-\mathcal{A}_{-i}}$.

I compare the seller's expected profits for two different price choices. We know that they have to be equal if we want her to randomize between them (or other prices with an identical outcome): $\pi_{i}\left(p_{1}\right)=\pi_{i}\left(p_{2}\right), \forall p_{1}, p_{2} \in\left(a_{i}, b_{i}\right]$. This equation gives us the relationship

$$
\frac{p_{1} D\left(p_{1}\right)}{p_{2} D\left(p_{2}\right)}=\frac{1+c_{i}\left(\prod_{j \neq i}\left(1-\beta_{j}\left(p_{2}\right)\right)-1\right)}{1+c_{i}\left(\prod_{j \neq i}\left(1-\beta_{j}\left(p_{1}\right)\right)-1\right)} .
$$

I use $a_{i}$ as the reference value, ${ }^{31}$ and the fact that $\beta_{j}\left(a_{i}\right)=0 \forall j>i$ and $\beta_{j}(p)=$ $0 \forall j, a_{j} \geq p$ to get the equality

$$
\frac{a_{i} D\left(a_{i}\right)}{p D(p)}=\frac{1+c_{i}\left(\prod_{j, a_{j}<p \& j \neq i}\left(1-\beta_{j}(p)\right)-1\right)}{1+c_{i}\left(\prod_{j<i}\left(1-\beta_{j}\left(a_{i}\right)\right)-1\right)} .
$$

Rearranging the terms, I get one equation from the system defining the mixing function

$$
\prod_{j, a_{j}<p \& j \neq i}\left(1-\beta_{j}(p)\right)=\left(1+c_{i}\left(\prod_{j<i}\left(1-\beta_{j}\left(a_{i}\right)\right)-1\right)\right) \frac{a_{i} D\left(a_{i}\right)}{c_{i} p D(p)}-\frac{1-c_{i}}{c_{i}}=: k_{i}(p) .
$$

If I use a logarithm for every equation from the system,

$$
\prod_{j, a_{j}<p \& j \neq i}\left(1-\beta_{j}(p)\right)=k_{i}(p), i=1 \ldots m, m=\max _{l}\left(a_{l}<p\right)
$$

\footnotetext{
${ }^{31}$ Though $a_{i}$ lies outside the interval $\left(a_{i}, b_{i}\right)$, I can use the limit $p_{1} \rightarrow a_{i}+$ to verify the correctness of this equation. The proof that $a_{i}$ cannot be chosen with a positive probability is straightforward.
} 
I get a system of linear equations:

$$
\sum_{j, a_{j}<p \& j \neq i} \log \left(1-\beta_{j}(p)\right)=\log \left(k_{i}(p)\right), i=1 \ldots m, m=\max _{l}\left(a_{l}<p\right) .
$$

I think of the expressions $x_{i}(p)=\log \left(1-\beta_{i}(p)\right)$ as unknowns. Then assigning $y_{i}(p)=\log \left(k_{i}(p)\right)$, vectors $X(p)=x_{i}(p), \quad Y(p)=y_{i}(p)$ the system of equations can be rewritten as $\mathrm{AX}=\mathrm{Y}$, where $\mathrm{A}$ is a matrix of ones with zeroes on the diagonal. The solution of the system is $x_{i}=\sum_{j, a_{j}<p} y_{j} /(m-1)-y_{i}$. Solving the substitution I get the formula for $\beta_{i}(p)$ :

$$
\beta_{i}(p)=1-\frac{\prod_{j, a_{j}<p} k_{j}^{\frac{1}{m-1}}}{k_{i}} .
$$

I need to determine the values of $a_{i}$ to finish the analysis. Observe that the distribution function $\beta_{i}$ of at least one player cannot have a mass point in the monopoly price. If every distribution function had one, the undercutting process would start. Also, $\beta_{i}\left(p_{M}-\epsilon\right)<1, \forall i, \epsilon>0$. If some player sets $\beta_{i}\left(p_{M}-\epsilon\right)=1$, a gap in the distribution function of other players would emerge between $p_{M}-\epsilon$ and $p_{M}$ and thus, the strategy of player $i$ would be sub-optimal.

Assume that the mixing function of player $i$ satisfies $\lim _{p \rightarrow p_{M}} \beta_{i}(p)=1 .^{32}$ Then, using equation $(2.7), \forall l \neq i, \lim _{p \rightarrow p_{M}} k_{l}(p)=0$. The equation can be translated to

$$
\left(\alpha_{l}+(1-\mathcal{A})\left(\prod_{j<l}\left(1-\beta_{j}\left(a_{l}\right)\right)\right)\right) a_{l} D\left(a_{l}\right)=\alpha_{l} p_{M} D\left(p_{M}\right)
$$

This equation says that $a_{l}$ is chosen so that the expected profit setting the price to $a_{l}$ equals the expected profit when the price is set equal to the monopoly price and selling only to uninformed buyers. The assumed properties of the function $D(\cdot)$ (or $p D(p)$ ) ensure the uniqueness of the solution. It means the equation has a unique solution for $a_{l}, l \neq i$. If seller l's mixing interval lower boundary would

\footnotetext{
${ }^{32} \mathrm{I}$ know there is at least one - the one whose distribution function does not have a mass point in $p_{M}$.
} 
be higher, $\hat{a}_{l}>a_{l}$, then $\hat{\beta}_{i}(p)<\beta_{i}(p), i<l, p \in\left(a_{l}, \hat{a}_{l}\right) .{ }^{33}$ This would mean that seller $l$ would get a higher profit choosing $p \in\left(a_{l}, \hat{a}_{l}\right)$ than what she would get in equilibrium, $\alpha_{l} p_{M} D\left(p_{M}\right)$. Therefore choosing any lower bound other than $a_{l}$ is not an equilibrium strategy.

The above derived formula also gives us the reason why $a_{l}, l \neq i$ are sorted increasingly $a_{1} \leq a_{2} \leq \cdots \leq a_{N}$. The proof by contradiction is apparent. I show later that even the value $a_{i}$ itself is sorted in the chain.

I need to analyze the two following cases. In the first case, the two least powerful sellers have the same market share, or $\alpha_{1}=\alpha_{2}$. In the second case, the least powerful seller has a strictly smaller market share than all other sellers, or $\alpha_{1}<\alpha_{2}$. I continue the analysis with the more complicated second case.

From the previous analysis, I know that the lower bounds of the distribution functions $a_{i}$ are specified by the above-mentioned formula except, possibly, for one. Assume that all $a_{i}$ are given by formula (2.8), then inequality $a_{1}<a_{2} \leq \cdots \leq a_{N}$ holds. However in that case, seller 1 would choose a sub-optimal strategy, and she would prefer to shift the lower bound $a_{1}$ upwards. In other words, there must be at least two players choosing the smallest value of the lower bound of their mixing probability function support. This implies that if $a_{1}$ is derived from equality (2.8), there must be $a_{i}$ such that $a_{i}=a_{1}$. Seller $i$ would, however, make a mistake doing this because she would lower her expected profit and prefer to choose the price $p_{M}$. Therefore, player 1 must be the one who does not set the lower bound $a_{1}$ according to formula (2.8). The value of $k_{1}\left(p_{M}\right)>0$ and due to equality (2.7), all other players choose the monopoly price with a positive probability.

I still need to find the value of $a_{1}$. The selection of $a_{1}=a_{2}$ is an equilibrium choice. I need to show that it is a unique choice that leads to an equilibrium. If seller 1 chooses a smaller value of the lower bound $a_{1}<a_{2}$, she would not gain the maximum expected profit. If seller 1 chooses a lower bound bigger than $a_{2}$, other players will adapt to her choice and select strategies such that player 1 gets a higher

\footnotetext{
${ }^{33}$ This follows directly the formula for $\beta_{i}(p)$ and the fact that $k_{i}(p)<1, p>a_{i}$.
} 
profit than choosing $a_{1}=a_{2}$. There is no reason, however, why seller 2 would not mimic player 1's strategy and obtain a higher expected profit. That would not be an equilibrium, however, because it has been proven that seller 2 chooses the lower bound $a_{2}$ with respect to equation (2.8). Therefore, the choice $a_{1}=a_{2}$ is the unique equilibrium choice. Also, this is the final fragment from the proof of the inequality chain $a_{1} \leq a_{2} \leq \cdots \leq a_{N}{ }^{34}$

The first case, when there are at least two sellers with the same, smallest market share is easier to analyze. There is an obvious equilibrium when every seller chooses the lower bound according to formula (2.8), and all mixing functions are continuous everywhere. I need to review the situation when one player chooses a different lower bound. When one player chooses a different lower bound $a_{i}$ than the one derived from equation (2.8), she must get a higher expected profit (she does not want to get a lower expected profit). There is always a player who would be willing to mimic player $i^{\prime}$ s strategy and grab the same profit. Then we would have two players not following equation (2.8), which is ruled out in an equilibrium.

We see that the equilibrium of the most complex model corresponds to, and includes, all three specific models presented before. The model describes symmetric competition and asymmetric competition of two or more sellers. The main feature, the uniqueness of the solution, remains preserved even in the most complicated setup. The equilibrium uniqueness implies that even in a finitely repeated competition model, the equilibrium remains unique and fully defined by the proposed generalmodel solution. The general model applies even to finitely repeated competition with variable market shares if current actions do not change future market share.

Compared to welfare implications derived from the three previously analyzed models, there are no qualitatively new results in this general model. I can, however, summarize and generalize those presented earlier.

I have distinguished three groups of agents in the analysis: sellers, informed buyers, and uninformed buyers. The expected profit of sellers is always equal to

\footnotetext{
${ }^{34}$ In fact, the first inequality holds with equality.
} 
the profit they would gain from selling to their market share at the monopoly price with one exception - the seller with the smallest market share (the "weakest" seller), who obtains almost the same expected profit as the second-weakest seller (with the difference of the profit from uninformed buyers at the lower bound). Every seller has an expected profit proportional to her own market share; only the uniquely weakest seller's expected profit is driven, apart from luck, by the expected profit of the second-weakest seller. This exception has more impact as the gap widens between the uniquely weakest seller and the second-weakest seller.

The buyers are assumed to be informed or uninformed, and uninformed buyers rely on the sellers to which they go. Their individual expected profit is higher if their seller is weaker (again, with the exception of the weakest seller). Informed buyers benefit from market fragmentation the most. For them, it is beneficial to face many weak sellers, and strong sellers do not have a significant impact on their profit because they do not push the prices down. In the exceptional case, with the existence of one (uniquely) weakest seller, the shift of the lower bound of the weakest seller's mixing interval subsequently increasing the seller's welfare is absorbed by the corresponding uninformed buyers (and there are few of them as the seller is the weakest one) and, more importantly, by the informed buyers. Informed buyers are, therefore, heavily dependent on the market structure, especially on the market shares of the weakest sellers.

\section{Conclusion}

In this paper, I have developed an oligopolistic model of sellers who compete on price for informed buyers, and have secured their share of uninformed buyers. Informed buyers know which seller sets the lowest price, and uninformed, or "loyal", buyers do not search for the lowest price but go to one seller only without knowing ex-ante his posted price. The basic, and for the result crucial, difference from previously published models is the reservation values of buyers. In the model presented in this paper, the reservation values are randomly drawn from a common distribution function rather than a pre-defined single value that has been used previously 
in the existing literature.

I have found that there is a unique mixed-strategy, Nash equilibrium of this model. In the equilibrium, every seller chooses randomly a price between an endogenously determined lower bound and the monopoly price associated with the demand function generated by the reservation value distribution function. Compared to the theoretical and empirical results of Kocas and Kyiak (2006), the model presented in this paper, namely the equilibrium strategy of sellers, explains the empirical findings of Kocas and Kyiak better than their own theoretical model. The main difference is that in my models all sellers, not just the two weakest, choose their prices randomly from a non-trivial interval.

There are several welfare implications in the result. As derived in the text, the expected profit, or the seller's surplus, is equal to the profit that every seller would get setting the monopoly price and selling to her share of the market (to the uninformed buyers who visit this seller) plus the difference between the 'market share value' of the two weakest sellers. ${ }^{35}$ As for buyers, the non-searchers' surplus increases with increased competition between sellers and a constant amount of searchers. Searchers benefit from increased competition in every situation with one exception.

The interesting exception from the rule "bigger competition = bigger buyer surplus" is the entry of a new seller who becomes the uniquely weakest one on the market. Imagine there are several sellers, and all with a positive market share. If a seller with no market share enters, she gets the expected profit close to the profit of the second weakest seller and thus steals a share of the total surplus. As the expected profit of the incumbent sellers does not change, their share on the total surplus remains constant. Therefore, the entrant steals the surplus fully from buyers.

The model applies to many areas. It naturally follows and generalizes the lit-

\footnotetext{
${ }^{35} \mathrm{~A}$ seller becomes weaker as a smaller amount of uninformed buyers come to her. The lower bound of the mixing strategy support of the two weakest sellers is identical - the same result as in the findings of Kocas and Kyiak.
} 
erature originated in Varian's article and also the vast literature on the Hotelling lemma: the size and distribution of the network of stores influences the size of the seller's market share. In fact, the present paper integrates the two concepts into one model: oligopolistic competition is introduced into Varian's model. Another straightforward application, apart from the analysis of concentration/location of stores, would be a study of advertisement from a competitive (not demand enhancing) point of view.

As a theoretical extension of the model, I would like to study further the introduction of production costs, the introduction of costs to increase market share (the model would approach the literature on promotions), and the introduction of search costs (the model would approach the literature on search mentioned in the introduction). It would also be interesting to introduce bounded rationality or incomplete information into the model. ${ }^{36}$ Sellers, for example, might not know the competitors' market shares and may just have estimates. It might be interesting to develop some kind of learning model that would fit reality better than the existing models do, the present one included.

\footnotetext{
${ }^{36}$ This extension would target the field of experimental economics; see, for example, Huck, Muller, and Vriend (2002).
} 


\section{References}

Baye, Michael R., and Casper G. De Vries, 1992. Mixed Strategy Trade Equilibria. The Canadian Journal of Economics 25(2), 281-93.

Braverman, Avishay, 1980. Consumer Search and Alternative Market Equilibria. Review of Economic Studies 47, 487-502.

Burdett, Kenneth, and Kenneth L. Judd, 1983. Equilibrium Price dispersion. Econometrica 51, 955-70.

Clay, Karen, Krishnan Ramayya, Eric Wolff, and Danny Fernandes, 2002. Retail Strategies on the Web: Evidence from the Online Book Industry. The Journal of Industrial Economics 50(3), 351-367.

Clemons, Eric K., Il-Horn Hann, and Lorin M. Hitt, 2002. Price Dispersion and Differentiation in Online Travel: An Empirical Investigation. Management Science 48(4), 534-549.

Huck, Steffen, Wieland Muller, and Nicolaas J. Vriend, 2002. The East End, the West End, and King's Cross: On Clustering in the Four-Player Hotelling Game. Economic Inquiry 40(2), 231-240.

Iyer, Ganesh, and Amit Pazgal, 2003. Internet Shopping Agents: Virtual CoLocation and Competition. Marketing Science 22(1), 85-106.

Kocas, Cenk, and Tunga Kiyak, 2006. Theory and Evidence on Pricing by Asymmetric Oligopolies. International Journal of Industrial Organization 24, 83-105.

Narasimhan, Chakravarthi, 1988. Competitive Promotional Strategies. The Journal of Business 61(4), 427-449.

Neven, D., G.Norman, and J.F.Thisse, 1991. Attitudes Towards Foreign Products and International Price Competition. The Canadian Journal of Economics 24(1), $1-11$.

Raju, J.S., V.Srinivasan, and R.Lal, 1990. The Effects of Brand Loyalty on Competitive Price Promotional Strategies. Management Science 276-304. 
Reinganum, Jennifer F., 1979. A Simple Model of Equilibrium Price Dispersion. Journal of Political Economy 87, 851-58.

Salop, Steven C., and Joseph E. Stiglitz, 1979. Bargains and Ripoffs: A Model of Monopolistically Competitive Price Dispersion. Review of Economic Studies 44, 493-510.

Sinitsyn, Maxim, 2008. Characterization of the Support of the Mixed Strategy Price Equilibria in Oligopolies with Heterogeneous Consumers. Economics Letters $99(2), 242-245$.

Stahl, Dale O., 1989. Oligopolistic Pricing with Sequential Consumer Search. The American Economic Review 79(4), 700-12.

Stiglitz, Joseph E., 1987. Competition and the Number of Firms in the Market. Journal of Political Economy 95, 1041-61.

Stiglitz, Joseph E., 1979. Equilibrium in Product Markets with Imperfect Information. The American Economic Review 69, 339-45.

Varian, Hal R., 1980. A Model of Sales. The American Economic Review 70(4), $651-59$.

Wilde, Louis L., and Allan Schwartz, 1979. Equilibrium Comparison Shopping. Review of Economic Studies 46, 543-53. 


\section{Working Paper Series}

ISSN 1211-3298

Registration No. (Ministry of Culture): E 19443

Individual researchers, as well as the on-line and printed versions of the CERGE-EI Working Papers (including their dissemination) were supported from the following institutional grants:

- Economic Aspects of EU and EMU Entry [Ekonomické aspekty vstupu do Evropské unie a Evropské měnové unie], No. AVOZ70850503, (2005-2010);

- Economic Impact of European Integration on the Czech Republic [Ekonomické dopady evropské integrace na ČR], No. MSM0021620846, (2005-2011);

Specific research support and/or other grants the researchers/publications benefited from are acknowledged at the beginning of the Paper.

(c) Michal Ostatnický, 2010

All rights reserved. No part of this publication may be reproduced, stored in a retrieval system or transmitted in any form or by any means, electronic, mechanical or photocopying, recording, or otherwise without the prior permission of the publisher.

Published by

Charles University in Prague, Center for Economic Research and Graduate Education (CERGE) and

Economics Institute ASCR, v. v. i. (EI)

CERGE-El, Politických vězňủ 7, 11121 Prague 1, tel.: +420 224005 153, Czech Republic.

Printed by CERGE-EI, Prague

Subscription: CERGE-EI homepage: http://www.cerge-ei.cz

Phone: + 420224005153

Email: office@cerge-ei.cz

Web: http://www.cerge-ei.cz

Editor: Byeongju Jeong

Editorial board: Jan Kmenta, Randall Filer, Petr Zemčík

The paper is available online at http://www.cerge-ei.cz/publications/working_papers/.

ISBN 978-80-7343-211-9 (Univerzita Karlova. Centrum pro ekonomický výzkum a doktorské studium)

ISBN 978-80-7344-201-9 (Národohospodářský ústav AV ČR, v. v. i.) 
CERGE-EI

P.O.BOX 882

Politických vězňů 7

11121 Praha 1

Czech Republic http://www.cerge-ei.cz 